\title{
Influence of the organophosphate insecticide fenthion on Mysidopsis bahia exposed during a complete life cycle I. Survival, reproduction, and age-specific growth*
}

\author{
Charles L. McKenney, Jr. \\ U.S. Environmental Protection Agency, Environmental Research Laboratory, Gulf Breeze, Florida 32561, USA
}

\begin{abstract}
Survival, growth, and various measures of reproductive performance were examined for an estuarine mysid, Mysidopsis bahia, throughout its life cycle during exposure to the organophosphate insecticide, fenthion (0,0-dimethyl 0-[3-methyl-4-(methylthio) phenyl] phosphorothioate). Concentrations of fenthion responsible for lethality $\left(300 \mathrm{ng} \mathrm{l}^{-1}\right)$ did not vary significantly between that observed after $4 \mathrm{~d}$ exposure of newly released juvenile mysids and that produced with continuous exposure through maturation and production of young. Exposure of maturing juveniles to $166 \mathrm{ng}$ fenthion $l^{-1}$ postponed the onset of reproduction by $4 \mathrm{~d}$. Both individual fecundity of females and total population production of young were reduced by fenthion concentrations of $79 \mathrm{ng} \mathrm{l}^{-1}$ and higher. Suppression of mysid growth rates was evident after only $4 \mathrm{~d}$ exposure of juvenile mysids to a sublethal fenthion concentration of $166 \mathrm{ng} \mathrm{l^{-1 }}$; a lower concentration $\left(79 \mathrm{ng} \mathrm{l}^{-1}\right)$ retarded growth rates of the more rapidly growing advanced juveniles after approximately 2 wk exposure. Reduced survival capacity, retarded growth rates, and diminished reproductive success of mysid populations with chronic, low-level exposure to fenthion would result in lowered production rates of an important prey population for commercially important fish that utilize the estuary as a nursery.
\end{abstract}

\section{INTRODUCTION}

Organophosphate insecticides have largely replaced organochlorine insecticides for many of the major insecticidal purposes in the United States (Eto 1974, Baron 1981). Fenthion (0,0-dimethyl 0-[3-methyl-4(methylthio) phenyl] phosphorothioate) is an example of such an organophosphate insecticide which is used against insects of public health concern (Mulla et al. 1979). However, population densities of not only freshwater insects but also crustaceans decreased at the site of aerial application of fenthion to a river and at several sites downstream (van Dyk et al. 1975). Such results are not surprising, considering the close phylogenetic relation between crustaceans and the insect pest toward which these insecticides are directed.

The close proximity of fenthion application to the highly productive estuarine ecosystem during the con-

- Contribution No. 552, Gulf Breeze Environmental Research Laboratory trol of saltmarsh mosquitoes affords concern for the possible hazard of this insecticide to the estuarine biotic community. Comparative $24 \mathrm{~h}$ toxicity tests with 5 estuarine organisms demonstrated that crustaceans were 2 to $4 \frac{1}{2}$ orders of magnitude more sensitive to fenthion than fish (Borthwick et al. 1985). These laboratory toxicity tests suggested that fenthion may be acutely toxic to estuarine crustaceans at concentrations approaching those encountered in normal use patterns for saltwater mosquito control.

To assess more thoroughly the potential biotic hazard of contaminants entering the estuarine environment, suitable criteria must be determined for detecting the ecological damage resulting from chronic sublethal exposure to low concentrations of these contaminants. Organismal responses to toxic substances which limit success of the population may ultimately result in structural and functional disruptions at the community and ecosystem levels (National Academy of Science 1971, Waldichuk 1979, Kinne 1980 , Sheehan 1984). Alterations in growth and reproductive 
success of individuals eventually influence the population by reducing abundance and modifying age structure within the population and, further, through population interactions may ultimately impact higher levels of biological organization.

An estuarine mysid Mysidopsis bahia has been shown to be very sensitive to a variety of toxic substances, particularly pesticides, when compared with other marine species (for review, see Nimmo \& Hamaker 1982). Increased mortality, growth retardation, and diminished reproductive success of this zooplankter with chronic exposure to low concentrations of pesticides directly impair production efficiency of the population (McKenney 1982, 1985). Reductions in the productivity of mysid populations could influence the trophodynamic processes of the estuarine community, since this crustacean serves as an important link in the estuarine food chain between primary producers and commercially important fish utilizing the estuary as a nursery (Odum 1971, Chao \& Musick 1977, Mauchline 1980).

The objectives of this research were to determine: (1) lethal concentrations of fenthion for Mysidopsis bahia exposed through a complete life cycle; (2) whether sublethal concentrations of fenthion alter the reproductive success of exposed mysids; and (3) the influence of chronic sublethal exposure to fenthion on agespecific growth rates of mysids during different life stages. Dose-response relations are developed and compared for the various biological functions. In addition, the various concentration-dependent responses of mysids to fenthion are evaluated on the basis of their ecological significance.

\section{MATERIALS AND METHODS}

Exposure system. Replicate groups of Mysidopsis bahia were exposed to fenthion through an entire life cycle, using a proportional diluter as described by Schoor \& McKenney (1983). Every $3 \mathrm{~min}$, the diluter produced $1 \mathrm{l}$ of filtered $(20 \mu \mathrm{m})$ seawater for each of 5 fenthion exposure concentrations and a carrier control. All exposure conditions contained $5 \mu$ l of the carrier (triethylene glycol) $1^{-1}$. Each liter was delivered to a glass aquarium divided into 3 replicate chambers $(58 \times 16 \times 27 \mathrm{~cm})$. As each chamber achieved its maximum volume of 121 , a self-starting siphon drained the water to a volume of 21 . Seawater in the exposure system was maintained at $20 \pm 2 \%$ salinity and $25 \pm 1{ }^{\circ} \mathrm{C}$.

Throughout the course of the study, fenthion concentrations for each exposure condition were determined weekly by gas chromatography using a procedure described by Lores et al. (1985). Measured fenthion concentrations (mean \pm standard error) were 0 (carrier control, below detection limit of $10 \mathrm{ng} \mathrm{l}^{-1}$ ), $16 \pm 4, \quad 37 \pm 10,79 \pm 18, \quad 166 \pm 23$, and $300 \pm 45 \mathrm{ng}$ fenthion $1^{-1}$.

Experimental procedures for survival and reproduction measurements. Newly released juvenile mysids ( $<24 \mathrm{~h}$ old) were obtained from ovigerous females maintained in static, recirculating culture with the same salinity-temperature conditions as the exposure system. Fifteen of these juveniles were pipetted into Nitex ${ }^{(8)}$ baskets constructed of $15 \mathrm{~cm}$ glass Petri dishes to which a $15 \mathrm{~cm}$ high cylinder of nylon screen (mesh $210 \mu \mathrm{m}$ ) was attached by silicone cement. Each basket was placed in one of 3 replicate chambers for each exposure concentration. Similar groups of mysids were placed in separate baskets at each exposure concentration for subsequent subsampling for growth measurements. Throughout the study, all groups of mysids were fed an abundance of freshly hatched Artemia nauplii daily.

Exposed mysids were observed daily for survival at each exposure concentration. As juveniles matured, ovigerous females were isolated in pairs with mature males within Nitex ${ }^{\otimes}$ brood cups constructed of $6 \mathrm{~cm}$ glass Petri dishes to which a $15 \mathrm{~cm}$ high cylinder of nylon screen (mesh $210 \mu \mathrm{m}$ ) was attached. Daily records were maintained for the day of release of the first brood and number of young released in the first brood by isolated females. The study was terminated 1 wk after the mean day of release of the first brood by control mysids, since past experience has shown that any toxicant-induced delay in release of young occurs within 1 wk.

Procedures and calculations for growth measurements. On days representative of various mysid life stages (Day 0, newly released juvenile; Day 4, early juvenile; Day 9, juvenile; Day 16, advanced juvenile/ young adult), 8 mysids were subsampled from each fenthion concentration. Each individual was briefly rinsed in distilled water and placed in an oven at $60^{\circ} \mathrm{C}$ to dry for $48 \mathrm{~h}$. Dry weights of individual mysids were subsequently measured to the nearest $0.1 \mu \mathrm{g}$ on a Cahn 21 Automatic Electrobalance.

Several growth indices were calculated from the dry weights of each mysid life stage exposed to the various fenthion concentrations by the formulas of Winberg (1971) and Winberg et al. (1971). The mean specific rate of growth was calculated by the equation

$$
g_{n}=\frac{\left(\ln W_{n+1}-\ln W_{n}\right)}{t}
$$

\footnotetext{
(2) Trademark; Tobler, Ernst, and Trabor, Inc., Murray St., New York, NY. Mention of commercial products does not imply endorsement by the U.S. Environmental Protection Agency
} 
where $g_{n}=$ the mean specific rate of growth of a particular life stage $n_{i} W_{n+1}=$ the mean dry weight of life stage $n+1 ; W_{n}=$ the mean dry weight of life stage $n ; t=$ the number of days between life stage $n$ and life stage $n+1$. The mean specific rate of growth was incorporated into the formula

$$
G_{n}=\left(e^{g_{n}}-1\right)
$$

to quantify the fractional daily weight gain $\left(G_{n}\right)$ for each life stage under the various fenthion exposure concentrations. $G_{n}$ was multiplied by the replicate dry weights to produce values of daily weight gain $\left(\mu \mathrm{g} \mathrm{d}^{-1}\right)$ for each life stage-concentration combination.

Statistical analysis. Differences in biological responses for the various fenthion concentrations were analyzed by analysis of variance, using Dunnett's procedure for multiple means comparisons (Zar 1974). Relations between bioligical responses and fenthion exposure concentrations were examined by regression analysis, using both a linear and quadratic model, and by multiple regression analysis (McNeil et al. 1975, Box et al. 1978). The multiple regression model for growth was a 2-factor, second-order polynomial equation, in which the entire data set for daily weight gain was regressed on the quadratic function of mysid age and fenthion concentration:

$$
\begin{array}{r}
W G=b_{0}+b_{1} C O N C+b_{11} C O N C^{2}+b_{2} A G E+ \\
b_{22} A_{G E}+b_{12}(C O N C \times A G E)
\end{array}
$$

where $W G=$ the estimated daily weight gain $\left(\mu \mathrm{g} \mathrm{d}^{-1}\right)$; CONC and $\mathrm{AGE}=$ the linear effect of fenthion concentration and mysid age, respectively; $\mathrm{CONC}^{2}$ and $\mathrm{AGE}^{2}=$ the quadratic effect of fenthion concentration and mysid age, respectively; $\mathrm{CONC} \times \mathrm{AGE}=$ the linear by linear interaction between fenthion concentration and mysid age; $b_{0}, b_{1}$, etc. $=$ the regression coefficients (Meyers 1971, Alderdice 1972). Coefficients for regression curves and response surface curves were generated by the General Linear Model (GLM) procedure, while the curves were drawn using the PLOT procedure available in the Statistical Analysis System (Barr et al. 1976).

\section{RESULTS}

\section{Survival}

Continuous exposure to measured fenthion concentrations ranging from 16 to $300 \mathrm{ng} \mathrm{l}^{-1}$ produced differential survival patterns in populations of Mysidopsis bahia during an entire life cycle (Table 1). Four d of exposure to a concentration of $300 \mathrm{ng}$ fenthion $1^{-1}$ resulted in significant mortality $(92 \%, p<0.05)$ in juvenile mysids. Although exposure to $166 \mathrm{ng}$ fenthion
Table 1. Mysidopsis bahia. Survival percentage (mean \pm SE)

\begin{tabular}{|c|c|c|c|}
\hline \multirow{2}{*}{$\begin{array}{l}\text { Fenthion } \\
\left(\mathrm{ng} \mathrm{l}^{-1}\right)\end{array}$} & \multicolumn{3}{|c|}{ Day } \\
\hline & 4 & 9 & 16 \\
\hline 0 & $95 \pm 2$ & $93 \pm 4$ & $93 \pm 4$ \\
\hline 16 & $97 \pm 2$ & $95 \pm 5$ & $95 \pm 5$ \\
\hline 37 & $98 \pm 2$ & $98 \pm 4$ & $98 \pm 2$ \\
\hline 79 & $98 \pm 2$ & $95 \pm 2$ & $92 \pm 5$ \\
\hline 166 & $95 \pm 5$ & $83 \pm 10$ & $77 \pm 5$ \\
\hline 300 & $8 \pm 6^{a}$ & $0 \pm 0^{a}$ & $0 \pm 0^{a}$ \\
\hline
\end{tabular}
with continuous exposure to fenthion from release as juveniles until maturation

a Significantly different from the control $(0)(p<0.05)$

$1^{-1}$ reduced juvenile survival rates to less than $80 \%$ following $16 \mathrm{~d}$ of exposure, analysis of variance demonstrated that fenthion concentrations $\leq 166 \mathrm{ng}$ $1^{-1}$ produced no significant reductions in mysid survival through the juvenile phase of the life cycle.

The curvilinear function

SUR $=84.6948+0.1104 \mathrm{CONC}-0.0013 \mathrm{CONC}^{2}$

where SUR $=$ survival of Mysidopsis bahia from release as juvenile until production of first brood of young, $\mathrm{CONC}=$ the linear effect of fenthion $\left(\mathrm{ng} \mathrm{l}^{-1}\right)$, and $\mathrm{CONC}^{2}=$ the quadratic effect of fenthion, described the influence of continuous fenthion exposure on $M$. bahia survival through a complete life cycle better than the simple linear regression (Fig. 1). An

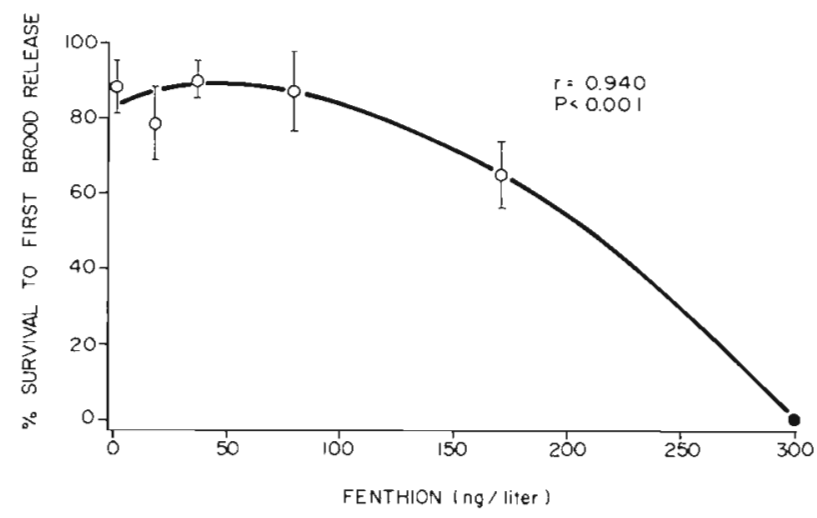

Fig. 1. Mysidopsis bahia. Survival percentage of population as a function of fenthion exposure through the complete life cycle. Values represent mean $\pm \mathrm{SE}$. Darkened circle is significantly different from control $(p<0.05)$

analysis of variance demonstrated no further reductions in mysid survival rates through release of their first brood at fenthion concentrations up to $166 \mathrm{ng} \mathrm{l}^{-1}$. 


\section{Reproduction}

Initiation of reproduction by Mysidopsis bahia was influenced by sublethal exposure to fenthion (Table 2). The linear function

$$
\mathrm{REL}=18.9686+0.0230 \mathrm{CONC}
$$

where REL = the mean day of release of the first brood, $\mathrm{CONC}=$ the linear effects of fenthion (ng $\mathrm{l}^{-1}$ ), best described the influence of fenthion exposure on the onset of reproduction by $M$. bahia (Fig. 2). Exposure to $166 \mathrm{ng}$ fenthion $\mathrm{l}^{-1}$ significantly delayed release of the first brood of $M$. bahia by $4 \mathrm{~d}$. Fenthion concentrations of $79 \mathrm{ng}^{-1}$ or less had no significant effects on initiation of production of young by mysids exposed throughout their life cycle.

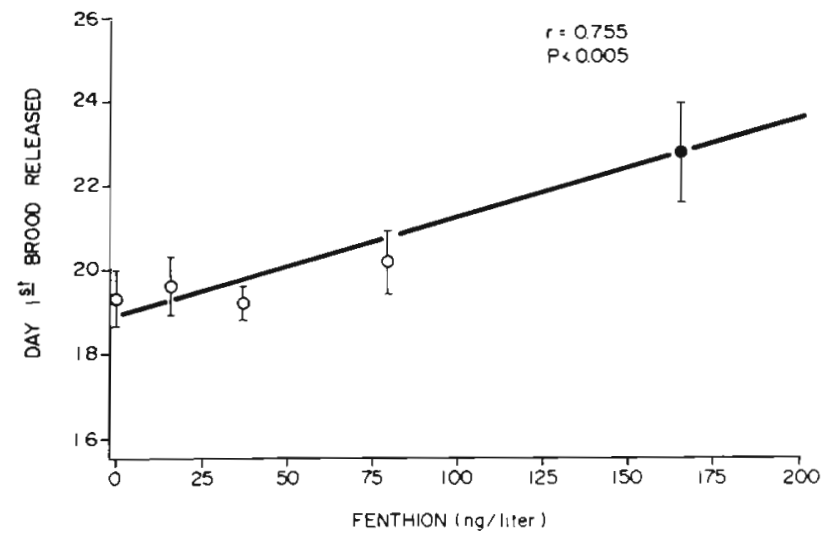

Fig. 2. Mysidopsis bahia. Mean day of release of first brood in population as a function of fenthion exposure through the complete life cycle. Values represent mean \pm SE. Darkened circle is significantly different from control $(p<0.05)$

Production of young by individual female mysids was modified by sublethal fenthion exposure throughout their life cycle (Table 2). The influence of fenthion on fecundity was best described by the curvilinear function

$\mathrm{YPF}=9.4098-0.0730 \mathrm{CONC}+0.0002 \mathrm{CONC}^{2}$ where YPF = the mean number of young produced per female in the first brood, and the other terms are as described for Eq. 4 (Fig. 3). Fenthion significantly reduced production of young from 9.0 per female in the first brood to 4.4 and 3.4 young in exposures of 79 and $166 \mathrm{ng} \mathrm{l}^{-1}$ respectively.

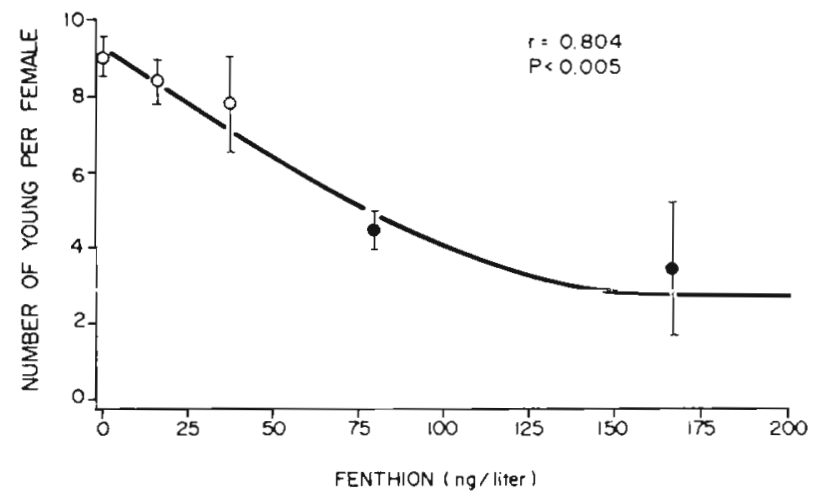

Fig. 3. Mysidopsis bahia. Number of young per female in population as a function of fenthion exposure through the complete life cycle. Values represent mean \pm SE. Darkened circles are significantly different from control $(p<0.05)$

As with individual female fecundity, total production of young by isolated mysid populations was significantly influenced by sublethal fenthion exposure through the life cycle of the individuals (Table 2). The effect of fenthion on first-brood production of young by Mysidopsis bahia was best described by the curvilinear regression

TYNG $=50.8630-0.3780 \mathrm{CONC}+0.0007 \mathrm{CONC}^{2}$

where TYNG = the total number of young produced by the first brood of the population, and the other terms are as previously described (Fig. 4). Continual lifecycle exposure to fenthion significantly reduced population production of young from 49.0 young in the first brood to 16.7 and 9.7 young in concentrations of 79 and $166 \mathrm{ng} \mathrm{l}^{-1}$ respectively.

Table 2. Mysidopsis bahia. Influence of continuous fenthion exposure through the complete life cycle on several reproductive responses. Each value represents mean $\pm \mathrm{SE}$

\begin{tabular}{|c|c|c|c|c|c|}
\hline \multirow[t]{2}{*}{ Reproductive response } & \multicolumn{5}{|c|}{ Fenthion (ng $\mathrm{l}^{-1}$ ) } \\
\hline & 0 & 16 & 37 & 79 & 166 \\
\hline Mean day of 1 st brood release & $19.4 \pm 0.7$ & $19.7 \pm 0.7$ & $19.3 \pm 0.5$ & $20.2 \pm 0.9$ & $23.4 \pm 0.6^{a}$ \\
\hline Number of young per female in 1 st brood & $9.0 \pm 0.6$ & $8.4 \pm 0.6$ & $7.8 \pm 1.3$ & $4.4 \pm 0.6^{\mathrm{a}}$ & $3.4 \pm 1.8^{\mathrm{a}}$ \\
\hline Total number of young in 1st brood & $49.0 \pm 14.6$ & $41.7 \pm 5.4$ & $49.7 \pm 9.6$ & $16.7 \pm 6.7^{a}$ & $9.7 \pm 7.8^{2}$ \\
\hline
\end{tabular}




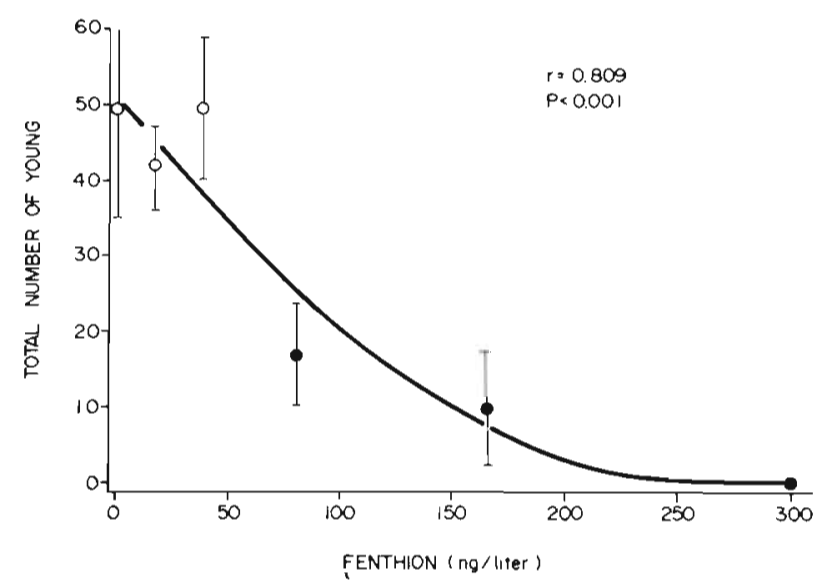

Fig. 4. Mysidopsis bahia. Total production of young by population as a function of fenthion exposure through the complete life cycle. Values represent mean $\pm \mathrm{SE}$. Darkened circles are significantly different from control $(p<0.05)$

\section{Growth}

An analysis of variance of age-specific growth rates $\left(\mu \mathrm{g} \mathrm{d}^{-1}\right)$ of various life stages of Mysidopsis bahia exposed to fenthion through a complete life cycle demonstrated that mysid growth rates were significantly ( $p<0.0001$ ) influenced by the age of the mysid, fenthion exposure concentration, and an interaction between these 2 factors. Since this analysis demonstrated that mysid growth was significantly influenced by an interaction between mysid age and exposure concentration of fenthion, growth rates of individual life stages were regressed on fenthion concentration (Fig. 5). The effects of fenthion exposure on growth rates of juvenile mysids during their first $4 \mathrm{~d}$ of existence were best described by the linear function

$$
\mathrm{WG}=48.7071-0.0760 \mathrm{CONC}
$$

where $W G=$ daily weight gain $\left(\mu \mathrm{g} \mathrm{d}^{-1}\right) ;$ CONC $=$ fenthion concentration (ng $\mathrm{l}^{-1}$ ) (Fig. 5A). Growth rates of early juvenile mysids were significantly $(p<0.05)$ retarded by $4 \mathrm{~d}$ of exposure to $166 \mathrm{ng}$ fenthion $\mathrm{l}^{-1}$, while exposure to concentrations $\leq 76 \mathrm{ng} \mathrm{l}^{-1}$ did not. The effects of fenthion on growth rates of juveniles between 4 and $9 \mathrm{~d}$ of age were best described by the curvilinear regression

$\mathrm{WG}=43.9477+0.2841 \mathrm{CONC}-0.0028 \mathrm{CONC}^{2}$

as shown in Fig. 5 B. During this period in the life cycle of $M$. bahia, growth rates were significantly retarded by $166 \mathrm{ng}$ fenthion $\mathrm{l}^{-1}$, but not influenced by any lower concentrations. The quadratic function

$\mathrm{WG}=87.9272+1.0395 \mathrm{CONC}-0.0216 \mathrm{CONC}^{2}$

best described the influence of fenthion on growth

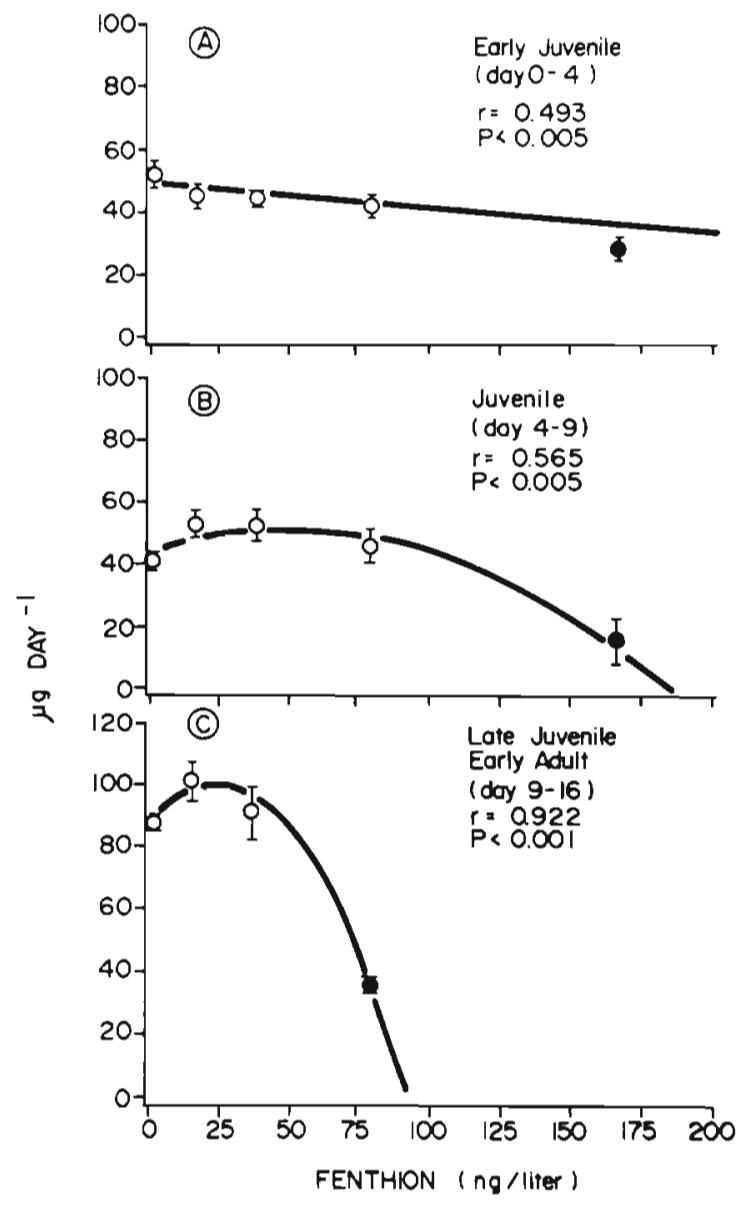

Fig. 5. Mysidopsis bahia. Growth rates $\left(\mu \mathrm{g} \mathrm{d}^{-1}\right)$ of various life stages as a function of continuous fenthion exposure through the complete life cycle. Values represent mean \pm SE. Darkened circles are significantly different from control $(p<0.05)$

rates of late juvenile and early adult mysids (Fig. 5C). Growth rates of these older juveniles were higher than for younger juveniles and their growth response to fenthion exposure was more curvilinear than that of the intermediate-aged juveniles with significant reductions in growth accompanying exposure to $76 \mathrm{ng}$ fenthion $\mathrm{l}^{-1}$.

To explore further the relations between mysid age and fenthion exposure on growth rates of Mysidopsis bahia, multiple linear regression analysis was performed on the entire growth data set (Table 3). This analysis suggested that mysid growth rates were most strongly influenced by an interaction between age of the mysid and fenthion exposure concentration. This relation is best depicted by the second-order polynomial function

$W G=46.2224+0.3474 \mathrm{CONC}-0.0012 \mathrm{CONC}^{2}-$ 2.0709AGE + 0.3139AGE ${ }^{2}-$

$0.0471(\mathrm{CONC} \times \mathrm{AGE})$ 
Table 3. Mysidopsis bahia. Multiple linear regression analy sis of daily growth rates $\left(\mu \mathrm{g} \mathrm{d}^{-1}\right)$ as influenced by age and continuous fenthion exposure from 16 to $166 \mathrm{ng} \mathrm{l}^{-1} . \mathrm{R}=0.810$

\begin{tabular}{|lrrrr|}
\hline $\begin{array}{l}\text { Source of } \\
\text { variation }\end{array}$ & DF & SS & F-value & p-value \\
\hline Total & 89 & 43129.03 & & \\
Model & 5 & 28290.25 & 32.03 & $<0.0001$ \\
CONC & 1 & 1130.16 & 6.40 & 0.0133 \\
CONC $^{2}$ & 1 & 235.43 & 1.33 & 0.2516 \\
AGE $_{\text {AGE }}^{2}$ & 1 & 626.69 & 3.55 & 0.0631 \\
CONC $\times$ AGE $_{\text {Error }}$ & 1 & 2389.92 & 13.53 & 0.0004 \\
& 84 & 4641.97 & 26.28 & $<0.0001$ \\
\hline
\end{tabular}

where $W G=$ daily weight gain $\left(\mu \mathrm{g} \mathrm{d}^{-1}\right)$, and the other terms are those described in Eq. 3. Response surface curves were developed from these coefficients to illustrate the relation of continuous fenthion exposure on mysid growth rates through one complete life cycle (Fig. 6). As shown by the intensity shading of the

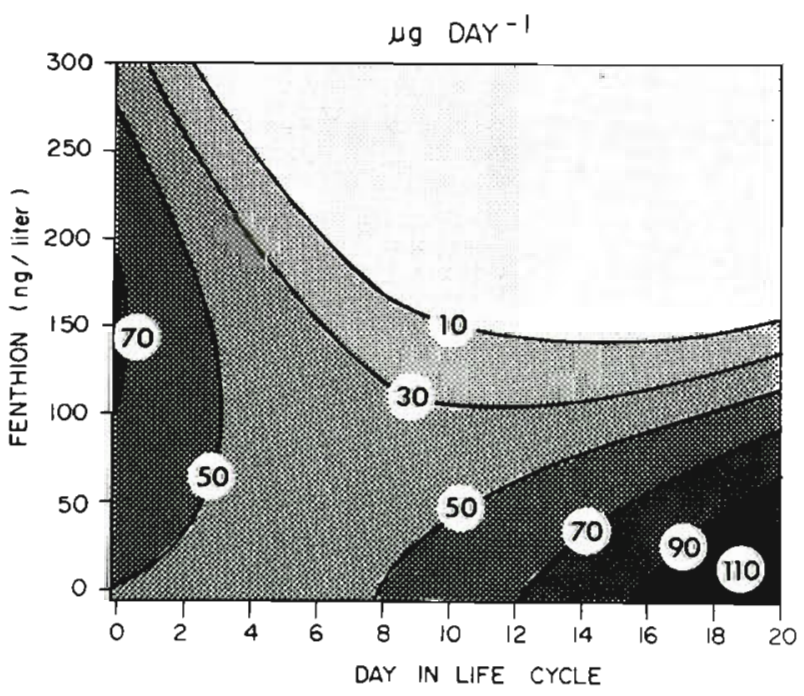

Fig. 6. Mysidopsis bahia. Response surface of growth rates as influenced by continuous fenthion exposure through the complete life cycle. The darker shading of the isopleths corresponds with the higher growth rates (numerically labeled $\mu \mathrm{g} \mathrm{d}^{-1}$ )

isopleths, mysid growth rates progressively increased through the juvenile period without fenthion exposure from less than $50 \mu \mathrm{g} \mathrm{d}^{-1}$ to more than $100 \mu \mathrm{g} \mathrm{d}^{-1}$ as young adults. Fenthion exposure had a minimal influence on early juvenile growth rates, but as juveniles developed and approached maturity, fenthion exposure retarded growth in a more linear fashion.

\section{DISCUSSION}

Mysidopsis bahia is one of the most sensitive nontarget aquatic organisms to the organophosphate insecticide fenthion with acute exposure. Acutely toxic concentrations of fenthion have been reported in the tenths of a $\mu \mathrm{g}^{-1}$ for juvenile pink shrimp Penaeus duorarum and juvenile $M$. bahia (Borthwick et al. 1985). A similar concentration of fenthion $\left(0.30 \mu \mathrm{g} \mathrm{l}^{-1}\right)$ resulted in acute lethality of juvenile $M$. bahia in this study. Juveniles of the estuarine caridean shrimp Palaemonetes pugio were slightly more resistant to fenthion ( $48 \mathrm{~h} \mathrm{LC50}, 5 \mu \mathrm{g} \mathrm{l}^{-1}$ ) whereas 2 estuarine fish species (Menidia beryllina and Cyprinodon variegatus) were much more resistant to fenthion $(48 \mathrm{~h}$ LC50 values of approximately $2000 \mu \mathrm{g} \mathrm{l}^{-1}$ ) (Borthwick et al. 1985). Fifty $\%$ mortality occurred among planktonic, estuarine copepods Acartia tonsa exposed to 500 $\mu \mathrm{g}$ fenthion $\mathrm{l}^{-1}$ (Newell et al. 1981). The sensitivity of a freshwater crustacean, Gammarus sp., to fenthion was of the same order $\left(48 \mathrm{~h} \mathrm{LC50}, 14 \mu \mathrm{g} \mathrm{l}^{-1}\right)$ as that of aquatic insect larvae ( $48 \mathrm{~h} \mathrm{LC50}$ of $12 \mu \mathrm{g} \mathrm{l^{-1 }}$ for both Chaoborus sp. and Cloeon sp.), but considerably higher than that of a freshwater mollusc $(48 \mathrm{~h}$ LC50, $6400 \mu \mathrm{g} \mathrm{l}^{-1}$ for Lymnea sp.) (Bluzat \& Seuge 1979).

Mortality patterns of Mysidopsis bahia exposed to fenthion during its entire life cycle suggest that early juvenile stages were the most sensitive to fenthion. Concentrations of fenthion responsible for direct lethality of $M$. bahia after $4 \mathrm{~d}$ exposure of newly released juvenile mysids did not vary significantly from those producing significant mortality with continuous exposure of juveniles for approximately $3 \mathrm{wk}$ through maturation and production of their first brood of young (Table 1 and Fig. 1). Such age-specific toxic effects would modify age structure of the population. Changes in the age structure of an important estuarine prey population, such as mysids, would alter the resource base for the predator populations and, ultimately, affect the dynamics of the commercially important fish species that use the estuary as a nursery (Odum 1971, Chao \& Musick 1977, Mauchline 1980).

While acute toxicity to individuals by a contaminant produces an obvious impact on the population, more subtle alterations in an organism's performance with chronic exposure to sublethal contaminant concentrations may result in an equally serious reduction in the ecological potential of the population. Successful reproduction is the single most important function in the life cycle of an organism and is essential for perpetuation of the species. As such, a definitive measure of the long-term impact of a sublethal concentration of a contaminant on the ecological fitness of a population is the capacity of the individuals to reproduce successfully (Waldichuk 1979, Kinne 1980, Sheehan 1984). 
Sublethal exposure of maturing Mysidopsis bahia juveniles to fenthion postponed the onset of reproduction. Time of release of the first brood was delayed by $4 \mathrm{~d}$ with exposure to $166 \mathrm{ng}$ fenthion $\mathrm{1}^{-1}$. Such a delay in age at first reproduction would result in a reduction in growth capacity of the population (Cole 1954, Allan 1976). Retarded maturation rates of the copepod Eurytemora affinis, following chronic exposure to the pesticides dieldrin (Daniels \& Allan 1981) and kepone (Allan \& Daniels 1982), contributed to reductions in the intrinsic rates of natural increase in the populations. Similarly, toxicant-induced postponements in the reproductive maturity of $M$. bahia exposed to sublethal concentrations of several heavy metals were, at least partially, responsible for reducing the populations' intrinsic growth rates (Gentile et al. 1982).

In addition to maturation delays, exposure to sublethal concentrations of fenthion reduced the individual fecundity of Mysidopsis bahia females. Exposure of maturing juvenile mysids to fenthion concentrations of 79 and $166 \mathrm{ng} \mathrm{l}^{-1}$ reduced young production in the first brood from 9 young per female to 4 and 3 young, respectively. Similarly, chronic exposure of the snail Lymnaea stagnalis to $2 \mathrm{mg}$ fenthion $\mathrm{l}^{-1}$ produced reductions in fecundity (Seuge \& Bluzat 1980). Only one of 5 other organophosphate pesticides, however, produced a reduction in reproductive activity in $M$. bahia with life-cycle exposure (Nimmo et al. 1981). Furthermore, the insecticide dimilin not only decreased young production of $M$. bahia exposed through its life cycle, but also affected reproduction of the progeny (Nimmo et al. 1980).

Alterations in reproductive success at the individual organism level ultimately impact the population by reducing abundance and changing the age structure of that population (Waldichuk 1979, Kinne 1980, Sheehan 1984). The consequences of lower fecundity of individual Mysidopsis bahia females with sublethal fenthion exposure was demonstrated at the next higher level of biological organization by reductions in the total number of young produced by isolated populations. Chronic exposure of discrete populations of juveniles through maturation and egg production to sublethal fenthion concentrations of 79 and $166 \mathrm{ng} \mathrm{l}^{-1}$ resulted in $66 \%$ and $80 \%$ fewer young being produced, respectively, in the first brood of each population. Were this inhibition in young production to continue with subsequent broods, modifications in the age structure of the population would follow. Similar to these results, production of fewer young by isolated populations of $M$. bahia accompanied reductions in the fecundity of individual females following sublethal, chronic exposure to 2 other pesticides (endrin and thiobencarb) (McKenney 1982, 1985).

In addition to sublethal alterations in the reproduc- tive capacity of Mysidopsis bahia with chronic, lowlevel exposure to fenthion, growth dynamics of mysids were modified and these retardations in growth rates varied with life stage. Suppression in growth rates was evident after only $4 \mathrm{~d}$ exposure of juveniles to fenthion. Lower concentrations ( $79 \mathrm{ng} \mathrm{l}^{-1}$ ) retarded growth in the more rapidly growing advanced juveniles after approximately $2 \mathrm{wk}$ exposure. The stronger influence of fenthion on growth rates of older than on younger juveniles could indicate increased sensitivity of older juveniles, greater impact of the pesticide after a longer exposure time with the potential for more bioaccumulation, or growth suppression being more evident during the most rapidly growing period in the juvenile phase of the life cycle. Similar interactions between growth retardation with pesticide exposure and mysid life stage have been reported for $M$. bahia exposed to a carbamate herbicide (McKenney 1985).

The concentrations of fenthion causing growth suppression in Mysidopsis bahia juveniles were ultimately the same as those associated with reproductive inhibition in adult mysids. Since brood production of $M$. bahia has been shown to be directly related to size of females such that brood size increases with increasing length (Price 1978), pesticide-induced growth retardation may be indirectly responsible for the reduced young production in $M$. bahia exposed sublethally to fenthion. In support of this contention, juvenile growth rates and reproductive success of this species were inhibited by the same concentrations of thiobencarb following entire life-cycle exposure (McKenney 1985). Similarly, chronic exposure of $2 \mathrm{mg}$ fenthion $\mathrm{l}^{-1}$ resulted in reductions in both fecundity and growth in the snail Lymnaea stagnalis (Seuge \& Bluzat 1980).

Since both egg production and growth are limited by the net balance between that portion of ingested energy which is assimilated and that which is lost through metabolic expenditures (Winberg 1971, Klekowski \& Duncan 1975), any disruption in normal metabolic processes may result in inefficient utilization of available energy and subsequent reductions in growth and reproduction. These lowered growth and reproductive capacities in Mysidopsis bahia with sublethal fenthion exposure may, therefore, be a result of increased metabolic maintenance demands and altered substrate utilization patterns, as previously demonstrated with chronic exposure of this species to 2 other pesticides (McKenney 1982, 1985).

Total population production among zooplankters is a product of growth and survival of all ages in the population and production of young by adults (Parsons 1980, Williams 1984). Stress from chronic pesticide exposure that reduces the individual's survival, reproductive, and growth capacity can have profound 
ecological consequences for the population. Moreover, for an important prey species, such as mysids (Odum 1971, Chao \& Musick 1977, Mauchline 1980), these population impacts have trophodynamic implications for the community. Reduced rates of secondary production in an important prey population (as exemplified in this study by reduced survival capacity, retarded growth rates, and diminished reproductive success of mysid populations) would alter the energy-flow patterns between connected trophic levels in the ecosystem. Although fenthion is directly toxic to estuarine fish only at unrealistically high environmental concentrations in the low $\mathrm{mg}^{-1}$ levels (Borthwick et al. 1985), lowered secondary production rates of mysid populations with exposure to low $\mathrm{ng} \mathrm{l}^{-1}$ concentrations of fenthion could reduce biomass and abundance in fish populations which depend upon mysids as an energy source and, ultimately, disrupt the trophic structure of the highly productive estuarine ecosystem.

The low concentrations of fenthion which produced reductions in growth rates and reproductive success of mysids in this study form the basis of concern for other estuarine crustaceans, including commercially important shrimp and crabs. Unlike mysids which produce multiple broods during their reproductive cycle, some other crustaceans breed as infrequently as annually or semi-annually. Sublethal inhibition of growth and reproduction with low-level pesticide exposure might have a more pronounced impact on these species with reproductive strategies different from mysids. Therefore, the potential exists for pesticide-induced dysfunction in the production processes of an important component of the estuarine community with a concurrent alteration in the trophodynamics of the estuarine ecosystem. Additional research on the influence of sublethal pesticide exposure on growth and reproduction of a variety of estuarine crustaceans could validate these concerns.

Acknowledgements. The valuable technical assistance of Ed Matthews and Debra Lawrence during portions of this study is gratefully acknowledged. Special thanks are extended to Johnnie Knight for his quantitative analyses for fenthion.

\section{LITERATURE CITED}

Alderdice, D. F. (1972). Factor combinations: responses of marine poikilotherms to environmental factors acting in concert. In: Kinne, O. (ed.) Marine ecology, Vol. I, Environmental factors, Part 3. Wiley, London, p. $1659-1722$

Allan, J. D. (1976). Life history patterns in zooplankton. Am. Nat. 110: 165-180

Allan, J. D., Daniels, R. E. (1982). Life table evaluation of chronic exposure of Eurytemora affinis (Copepoda) to kepone. Mar. Biol. 66: 179-184

Baron, R. L. (1981). Delayed neurotoxicity and other conse- quences of organophosphate esters. Ann. Rev. Entomol. 26: $29-48$

Barr, A. J., Goodnight, J. H., Sall, J. P., Helwig, J. T. (1976). A user's guide to SAS 76. Statistical Analysis Systems Institute, Inc., Raleigh

Bluzat, R., Seuge, J. (1979). Effets de trois insecticides (lindane, fenthion et carbaryl): toxicité aiguë sur quatre espèces d'invértébres limniques; toxicité chronique chez le mollusque pulmone Lymnea. Environ. Pollut. 18: 51-70

Borthwick, P. W., Clark, J. R., Montgomery, R. M., Patrick, J. M., Jr., Lores, E. M. (1985). Field confirmation of a laboratory-derived hazard assessment of the acute toxicity of fenthion to pink shrimp, Penaeus duorarum. In: Bahner, R. C., Hansen, D. J. (ed.) Aquatic toxicology and hazard assessment: eighth symposium. American Society for Testing and Materials, Philadelphia, p. 177-189

Box, G. E. P., Hunter, W. G., Hunter, J. S. (1978). Statistics for experimenters. John Wiley \& Sons, New York

Chao, L. N., Musick, J. A. (1977). Life history, feeding habits, and functional morphology of juvenile sciaenid fishes in the York River Estuary, Virginia. Fish. Bull. U.S. 75: $657-702$

Cole, L. C. (1954). The population consequences of life history phenomena. Q. Rev. Biol. 29: 103-137

Daniels, R. E., Allan, J. D. (1981). Life-table evaluation of chronic exposure to a pesticide. Can. J. Fish. Aquat. Sci. 38: 485-494

Eto, M. (1974). Organophosphorus pesticides: organic and biological chemistry. CRC Press, Cleveland

Gentile, J. H., Gentile, S. M., Hairston, N. G., Sullivan, B. K. (1982). The use of life-tables for evaluating the chronic toxicity of pollutants to Mysidopsis bahia. Hydrobiologia 93: $179-187$

Kinne, O. (1980). 14th European marine biology symposium "Protection of life in the sea": summary of symposium papers and conclusions. Helgoländer Meeresunters. 33: 732-761

Klekowski, R. Z., Duncan, A. (1975). Physiological approach to ecological energetics. In: Grodzinski, W., Klekowski, R. Z., Duncan, A. (ed.). Methods for ecological bioenergetics. Blackwell Scientific Publications, Oxford, p. 15-64

Lores, E. M., Moore, J. C., Knight, J., Forester, J., Clark, J. (1985). Determination of fenthion residues in samples of marine biota and seawater from laboratory exposure and field applications. J. Chromatogr. Sci. 23: 124-127

Mauchline, J. (1980). The biology of mysids and euphasiids. Part 1. The biology of mysids. Adv. mar. Biol. 18: 1-369

McKenney, C. L., Jr. (1982). Interrelationships between energy metabolism, growth dynamics, and reproduction during the life cycle of Mysidopsis bahia as influenced by sublethal endrin exposure. In: Vemberg, W. B., Calabrese, A., Thurberg, F. P., Vernberg, F. J. (ed.) Physiological mechanisms of marine pollutant toxicity. Academic Press, New York, p. 447-476

McKenney, C. L., Jr. (1985). Associations between physiological alterations and population changes in an estuarine mysid during chronic exposure to a pesticide. In: Vernberg, F. J., Thurberg, F. P., Calabrese, A., Vernberg, W. B. (ed.) Marine pollution and physiology: recent advances. University of South Carolina Press, Columbia, p. 397-418

McNeil, K. A., Kelley, F. J., McNeil, J. T. (1975). Testing research hypothesis using multiple linear regression. Southern Illinois University Press, Carbondale

Meyers, R. H. (1971). Response surface methodology, Allyn Bacon, Boston

Mulla, M. S., Majori, G., Arata, A. A. (1979). Impact of biological and chemical mosquito control agents on nontarget 
biota in aquatic ecosystems. Residue Reviews 71: 121-173 National Academy of Science (1971). Marine environmental quality. National Academy of Science, Washington

Newell, S. Y., Cooksey, K. E., Fell, J. W., Master, I. M., Miller, C., Walter, M. A. (1981). Acute impact of an organophosphorus insecticide on microbes and small invertebrates of a mangrove estuary. Archs environ. Contam. Toxicol. 10: $427-435$

Nimmo, D. R., Hamaker, T. L. (1982). Mysids in toxicity testing-a review. Hydrobiologia 93: 171-178

Nimmo, D. R., Hamaker, T. L., Moore, J. C, Wood, R. A. (1980). Acute and chronic effects of dimilin on survival and reproduction of Mysidopsis bahia. In: Eaton, J. G., Parrish, P. R., Henricks, A. C. (ed.) Aquatic toxicology. American Society for Testing and Materials, Philadelphia, p. 336-376

Nimmo, D. R., Hamaker, T. L., Matthews, E., Moore, J. C. (1981). An overview of the acute and chronic effects of first and second generation pesticides on an estuarine mysid. In: Vernberg, F. J., Calabrese, A., Thurberg, F. P., Vernberg, W. B. (ed.) Biological monitoring of marine pollutants. Academic Press, New York, p. 3-20

Odum, W. E. (1971). Pathways of energy flow in a south Florida estuary. University of Miami Sea Grant Program, Sea Grant Technical Bulletin No. 7, Miami

Parsons, T. R. (1980). Zooplankton production. In: Barnes, R. S. K., Mann, K. H. (ed.) Fundamentals of aquatic ecosystems. Blackwell Scientific Publications, Oxford, p. $46-66$

Price, W. W. (1978). Occurrence of Mysidopsis almyra Bowman, $M$. bahia Molenock and Bowmaniella brasiliensis Bacescu (Crustacea, Mysidacea) from the eastern coast of Mexico. Gulf Res. Rep. 6: 173-175
Schoor, W. P., McKenney, C. L., Jr. (1983). Determination of fenvalerate in flowing-seawater exposure studies. Bull. environ. Contam. Toxicol. 30: 84-92

Seuge, J., Bluzat, R. (1980). Toxicité à long terme d'un insecticide organophosphore (fenthion) chez le mollusque Lymnaea stagnalis L. Hydrobiologia 76: 241-248

Sheehan, P. J. (1984). Effects on individuals and populations. In: Sheehan, P. J., Miller. D. R., Butler, G. C., Bourdeau, Ph. (ed.) Effects of pollutants at the ecosystem level. John Wiley \& Sons, New York, p. 23-50

van Dyk, L. P., Greeff, C. G., Brink, J. J. (1975). Total population density of Crustacea and aquatic Insecta as a indicator of fenthion pollution of river water. Bull. environ. Contam. Toxicol. 14: 426-431

Waldichuk, M. (1979). Review of the problems. In: Cole, H. A. (ed.) The assessment of sublethal effects of pollutants in the sea. The Royal Society, London, p. 1-26

Williams, R. (1984). An overview of secondary production in pelagic ecosystems. In: Fasham, M. J. R. (ed.) Flows of energy and materials in marine ecosystems. Plenum Press, New York, p. 361-405

Winberg, G. G. (1971). Methods for the estimation of production of aquatic animals. Academic Press, New York

Winberg, G. G., Patalas, K., Wright, J. C., Hillbricht-Ilkowska, A., Cooper, W. E., Mann, K. H. (1971). Methods for calculating productivity. In: Edmondson, W. T., Winberg, G. G. (ed.) Secondary productivity in fresh waters. Blackwell Scientific Publications, Oxford p. 296-317

Zar, J. H. (1974). Biostatistical analysis. Prentice-Hall, Englewood Cliffs 